\title{
Application of the aggregated calculation algorithm EA FAHP and fuzzy TOPSIS methods in the evaluation of railway culverts serviceability
}

\author{
Dariusz Fabianowski ${ }^{1 *}$, and Przemystaw Jakiel ${ }^{2}$ \\ ${ }^{1}$ Dept. of Civil Engineering and Construction Processes, Faculty of Civil Engineering and \\ Architecture, Opole University of Technology, ul. Katowicka 48, 45-061 Opole, Poland \\ ${ }^{2}$ Dept. of Roads and Bridges, Faculty of Civil Engineering and Architecture, Opole University of \\ Technology, ul. Katowicka 48, 45-061 Opole, Poland
}

\begin{abstract}
Managing maintenance systems of railway culverts constitutes a typical multiple criteria decision related problem which arises from the necessity to allocate limited financial resources to repair work. Culverts are ranked on the basis of evaluation of their level of structure degradation obtained with the use of a properly created set of criteria. In order to fully present the specific character of the issue under scrutiny, an innovative approach has been proposed using the aggregated calculation algorithm which combines the EA FAHP and Fuzzy TOPSIS methods. It is a decision-making and calculation model which allows to reflect the actual evaluation processes, as well as to take into account the diversity of solutions with respect to materials applied in the structures of railway culverts.
\end{abstract}

\section{Introduction}

Culverts, which are extremely diversified with respect to static schemes and materials applied, constitute the largest group among engineering structures of land transport infrastructure. Moreover, quite a few of them were constructed as early as 19th century. Modernisation of Polish railways that has been carried out over the last few years with a significant support of the European Union funds, provides also for repair work of the existing culverts preceded by a thorough analysis of their technical condition. Due to a large number of such structures, quite frequently significantly exceeding the number of bridges, there occurs a necessity for maintenance services to efficiently manage culverts by making suitable decisions promptly with respect to their current and prospective serviceability. It is a multiple criterion issue as there are numerous factors that are of importance, for example technical condition of individual elements of a culvert, its bearing capacity, history of repair work etc.

Due to significance of the problem a method allowing to evaluate serviceability of structures of railway culverts, which is based on the aggregated model created by combin-

\footnotetext{
${ }^{*}$ Corresponding author: darof@o2.pl
} 
ing the modified EA FAHP and Fuzzy TOPSIS methods, was presented in this paper. The algorithm makes it possible to properly rank culverts with respect to the necessity to undertake repair work. It is of particular importance in order to maintain the required safety levels at such railways lines, as well as for their manager to allocate funds appropriately.

The authors of this paper made a decision to address the aforementioned problem upon failing to find any studies in world literature that would contain the application of methods for assisting the decision-making process with the use of the fuzzy set theory in the context of serviceability of railway culverts. The assumptions of the presented method, as well as its application, have been discussed in this paper on the example of six culvert structures.

\section{Subject of analysis}

Six railway culverts of diversified structures located on the railway line Kielce - Fosowskie (Fig. 1) are the subject of this analysis. There is a conventional track structure in the form of breakstone, RC sleepers and UIC60 rails present on all of them. Surface drainage was performed for all culverts and all of them are directly founded.

The load-bearing structure of the first culvert (km 120+196, dated of 1942) is in the form of a vault with diagonal expansion joints to create separate segments for under each rail. The length of segments under tracks 1 and 2 is $5.07 \mathrm{~m}$ and $4.80 \mathrm{~m}$ respectively. Theoretical span of the arch is $2.30 \mathrm{~m}$ and its thickness amounts to $30 \mathrm{~cm}$. There are also two headwalls with the width of $55 \mathrm{~cm}$ and the total culvert length is $10.25 \mathrm{~m}$. The structure is covered with heavy insulation made of thermo-welded roofing paper and a layer of lean concrete. The culvert is fitted out with steel railings with the height of $1.10 \mathrm{~m}$, fixed to the upper surface of the cornices.

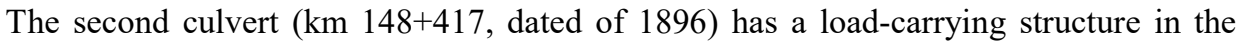
form of a monolithic single-span reinforced concrete slab and a stone slab, both supported on brick walls. Total length of the culvert amounts to $15.58 \mathrm{~m}$ and the theoretical span is 50 $\mathrm{cm}$. Thickness of the slab is $27 \mathrm{~cm}$ and the embankment over the culvert is limited by two $53 \mathrm{~cm}$-thick brick headwalls on which there are steel railings made of flat bars fixed to the concrete cornices.

The structure of the third culvert $(\mathrm{km} \mathrm{149+017}$, dated of 1952) is a RC pipe with the internal diameter of $38 \mathrm{~cm}$, thickness of $8 \mathrm{~cm}$ and total length of $11.94 \mathrm{~m}$. About $1 \mathrm{~m}$-long segments of prefabricated pipes are connected with the use of cement mortar. On both sides there about $40 \mathrm{~cm}$-thick and $2.32 \mathrm{~m}$-long headwalls with cornices whose width is $46 \mathrm{~cm}$. On the cornices of headwalls there are steel balusters made of tubular profiles with handrails made of angle bars.

The fourth culvert $(\mathrm{km} \mathrm{149+217}$, dated of 1952) has total length of $11.95 \mathrm{~m}$ and it is composed of a prefabricated reinforced concrete pipe with the internal diameter of $60 \mathrm{~cm}$ and thickness of $12 \mathrm{~cm}$. About $1 \mathrm{~m}$-long pipe sections are connected with the use of cement mortar. At the inlet and outlet there are about $40 \mathrm{~cm}$-thick headwalls with cornices that are about $45 \mathrm{~cm}$ wide.

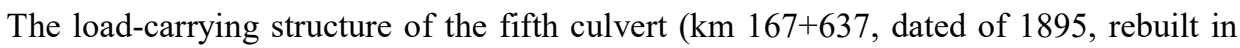
1964) is in the form of a $30 \mathrm{~cm}$-thick single-span RC simply supported slab. The structure is equipped with new cornices with the width of $52 \mathrm{~cm}$. Total length of the culvert (in watercourse axis) is $4.94 \mathrm{~m}$ and the internal horizontal and vertical clearance of this structure is $1.50 \mathrm{~m}$ and $0.80 \mathrm{~m}$ respectively. The culvert is covered with insulation made of thermo-welded roofing paper and a protection layer of concrete. The piers are in the form of solid brick abutments with wings parallel to the culvert axis.

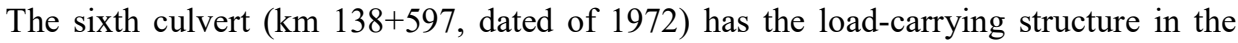
form of a RC double frame. $100 \mathrm{~cm} \times 100 \mathrm{~cm}$ closed section prefabricated elements were used. The recorded thickness of the upper frame spandrel beam is $16 \mathrm{~cm}$. The embankment 

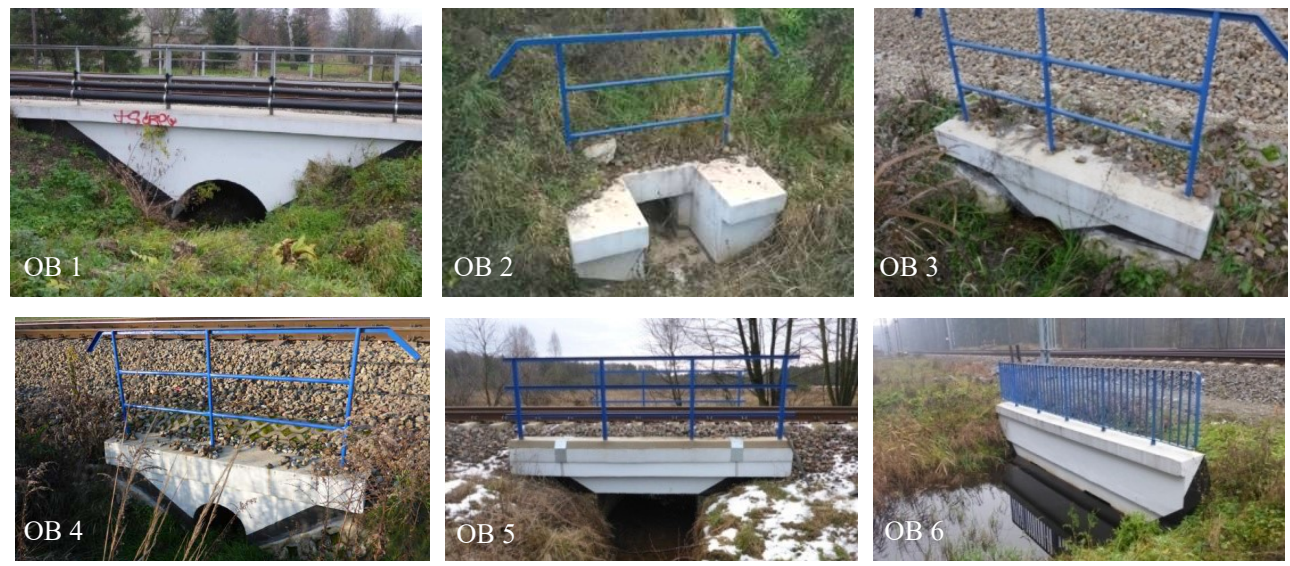

Fig. 1. View of the culverts under analysis (description within the text).

over the culvert is limited by two headwalls with the thickness of about $50 \mathrm{~cm}$. Total length of the culvert (in the axis) amounts to $16.52 \mathrm{~m}$.

All culverts under scrutiny were subjected to evaluation of their technical condition taking into consideration their load-bearing structures, piers, headwalls with the fittings and obstacles (Fig. 2). Most culverts have been repaired over the last few years with surface protection of headwalls and railings performed as main repair work.

Minor damage of the concrete elements of load-bearing structure, such as surface corrosion, leakage and efflorescence, was identified in the first culvert. Numerous damp stains created due to concrete elements being washed out prove that the insulation is not tight. Condition of the headwalls and wings does not give rise to any objections. The railings are in a very good shape and the watercourse bed within the area of the culvert is unregulated.
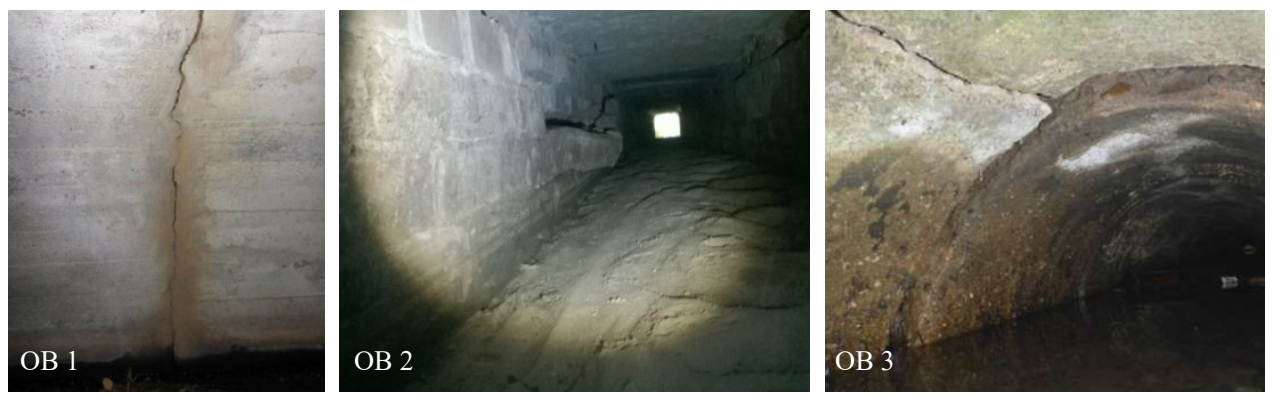

Fig. 2 Sample damage of culverts No. 1, 2 and 3 (description within the text).

Heavy contamination of stone slabs and material spalling were found on the entire internal surface of the span in culvert No. 2 and slab faulting occurred due to the damage of its piers. Technical condition of the span does not give rise to objections, no symptoms of the lack of tightness were found, however the brick walls were damaged to a significant degree and individual bricks had been displaced. Both headwalls and elements of the equipment are in a good condition, however watercourse bed is unregulated.

It was found that the RC pipe of the third culvert had cracked at the end segment on the inlet side and heavy contamination of concrete, in the form of surface corrosion, was visible on the internal surface of the prefabricated elements. Cement mortar joining the segments has deteriorated completely. Inside the culvert there are soil residues and the structure is partially silted. The cornice of the headwall is scratched but it is of no impact on the stability of the structure. Condition of the elements of fittings does not give rise to 
reservations but the watercourse bed within the culvert is unregulated and there is water continuously present in the culvert.

It was found that there were residues and contamination of concrete surfaces on the prefabricated pipe of culvert No. 4, but apart from that its condition was acceptable. The culvert is scratched at the contact point of headwalls and the prefabricated pipe, as well as on the surface of the cornice. Stream bed nearby the culvert is unregulated.

Condition of the slab carrier and brick piers of the fifth culvert do not give rise to any reservations. Local leaks and efflorescence were found on the left abutment on the inlet side. The remaining elements of the culvert are in a satisfactory condition.

In case of culvert No. 6 , no faults in the structure were found, however due to the fact that the clearance of the culvert was totally flooded, it was impossible to inspect the condition of the structure from the inside. Technical condition of headwalls and the fittings does not give rise to reservations. The recorded water level at the outlet reached the surface of the upper cross-bar of the culvert, which adversely affects stability of the embankment within the culvert.

\section{Methodology of proceeding}

\subsection{General assumptions}

The decision-making problem being analysed arises from the necessity to allocate limited financial resources to properly directed repair work of culverts. It is a multiple criteria issue consisting in the arrangement of such structures on the basis of their technical condition being decisive for their safety of use and, at the same time, providing the possibility to properly arrange the stages of the repair work to be carried out.

The suggested calculation model being a combination of the modified EA FAHP method [1,2] and the Fuzzy TOPSIS one [3] fully reflects the specific character of the problem and allows to analyse any number of objects. Initial assessments are obtained from standard periodical inspections and valuation of the technical condition of the structure, which is carried out in case of its failure. In exceptional cases the aforementioned can be performed on the basis of more detailed tests. The multi-year data thus obtained might be used to forecast the technical condition of culverts.

The model requires making the assessment scale uniform by assigning proper technical condition of particular culvert components to individual values $1 \div 9$ (Table 1 , columns 1,3 ).

Table 1. The applied linguistic assessment with the corresponding fuzzy numbers.

\begin{tabular}{|l|l|c|c|}
\hline \multicolumn{2}{|c|}{ Dominance scale / Linguistic assessment } & \multirow{2}{*}{$\begin{array}{c}\text { Corresponding } \\
\text { Fuzzy Number }\end{array}$} & $\begin{array}{c}\text { Reversed Fuzzy } \\
\text { Number } \\
\text { to criteria }\end{array}$ \\
\hline \multicolumn{1}{|c|}{ Facility condition in relation } & \multicolumn{1}{|c|}{ Criteria to each other } & 3 & 4 \\
\hline $1 /$ ideal & $1 /$ equivalence & $(1,1,1)$ & $(1,1,1)$ \\
\hline $2 /$ perfect* & 2 & $(1,2,4)$ & $(1 / 4,1 / 2,1)$ \\
\hline $3 /$ very good & $3 /$ minor dominance & $(1,3,5)$ & $(1 / 5,1 / 3,1)$ \\
\hline $4 /$ good $^{*}$ & 4 & $(2,4,6)$ & $(1 / 6,1 / 4,1 / 2)$ \\
\hline $5 /$ average & $5 /$ strong dominance & $(3,5,7)$ & $(1 / 7,1 / 5,1 / 3)$ \\
\hline $6 /$ bad* & 6 & $(4,6,8)$ & $(1 / 8,1 / 6,1 / 4)$ \\
\hline $7 /$ insufficient & $7 /$ very strong dominance & $(5,7,9)$ & $(1 / 9,1 / 7,1 / 5)$ \\
\hline $8 /$ pre-failure* & 8 & $(6,8,9)$ & $(1 / 9,1 / 8,1 / 6)$ \\
\hline $9 /$ failure prone & $9 /$ absolute dominance & $(7,9,9)$ & $(1 / 9,1 / 9,1 / 7)$ \\
\hline$* 2,4,6,8$ values constitute average grades in the assessment of criteria \\
\hline
\end{tabular}


The lowest rank, 1, corresponds to the design condition (ideal condition) and the highest, 9, denotes a failure (paradoxically, as it is in case of a stimulant the higher the degradation level the higher the assessment). The situation is similar to the one where objects were evaluated due to their age: the older the object, the higher the assessment. Such approach is consistent with the methodology of assessing the technical condition and the assessment representation with the use of fuzzy values perfectly reflects their subjective character, various precision and frequent lack of full information along with its ambiguity.

The algorithm of the suggested method was presented in Figure 3. The preliminary procedure consists in identifying and defining the aim of the analysis (Phase I). Creating a hierarchical tree of criteria and sub-criteria of assessment is the next step (Phase II). Phase III consists in calculating the weight vector of the criteria and sub-criteria carried out with the use of the modified EA FAHP method, with the application of a fuzzy equivalent of Saaty's evaluation scale (Table 1). Chang's method, belonging to the FGDM group of methods, has a relatively clear calculation algorithm and, moreover, it allows to make references to the classic Saaty's AHP method, which facilitates the assessment procedure. The applied modified EA FAHP method as suggested by Wang and Elhag [2] eliminates the possibility to obtain zero components of the weight vector in case of significant discrepancies of assessments (in practice, only a 5-grade scale is of use, which is insufficient in the issue under scrutiny [4]). Due to the lack of equivalent for fuzzy assessments, in order to approximately verify the correctness of the arrangement of assessments, the CR consistency ratio was used which is obtained for modal values of fuzzy numbers constituting assessments in matrices for comparison in pairs. Further procedure is analogous to the one in the classic AHP method. Final assessments are obtained by multiplying the values of weight vectors along the branches of the hierarchical tree. Phase IV consists in applying the Fuzzy TOPSIS algorithm to aggregate assessments at the lowest level of the hierarchical tree which leads to positioning objects on the basis of the obtained ranking vector (Phase V).

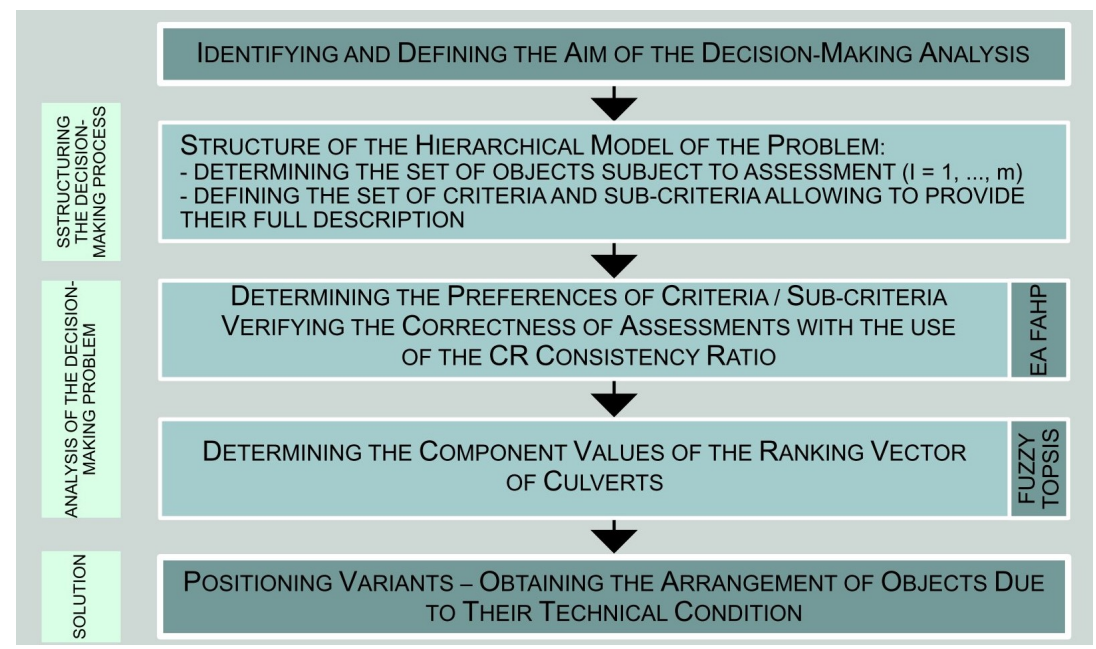

Fig. 3. Technique of order preference by similarity to ideal solution process flow.

\subsection{Evaluation criteria}

Evaluation criteria should compose a set that in a complex manner describes the techni-cal condition of a structure and that functions as a starting point for the maintenance ser-vices to take the key decisions connected with the optimum management of culverts. Due a 
significant number of 'classical' structure culverts demanding the aforementioned expert analyses, two dominating groups of criteria have been discussed within this article, that is:

A - the exploitation criterion - concerns the object meeting the assumed utility functions in the form of the age of the object (A1), evaluation of environmental factors influencing the structure (A2) and the quality of the so-far maintenance (A3),

$\mathrm{B}$ - the technical condition criterion - it is established individually depending on the level of wear of the components of a culvert dividing these into the structure of the conduit, headwalls, elements of fittings and obstacle.

The $\mathrm{B}$ criterion, which carries most weight, is the main criterion describing the current technical condition of a given culvert and influencing the overall rating of objects. The $\mathrm{A}$ criterion, on the other hand, although of a lower level of importance, determines the reason for the registered condition of a culvert as a rule. In connection with the aforementioned, the grade obtained pursuant to the B criterion does not always make it possible to determine the reasons but always facilitates undertaking proper repair work. It is believed that criteria of the A group, if determined in a professional manner, shall constitute a set of stable assessments not being subject to such significant changes in time as the B criterion grades are, which are dependent on the results of periodical inspections of the structure.

On the second level of the hierarchical tree, three and four sub-criteria were marked for the $\mathrm{A}$ and $\mathrm{B}$ criteria respectively. It was determined that the exploitation criterion shall take into account the age of the object (A1), environmental conditions in which it is located (A2) and the quality of the so-far maintenance (A3). Whereas the B criterion was divided into the sub-criterion of the technical condition of the conduit of a culvert (B1), headwalls (B2), the fittings (B3) and B4 - obstacle (Fig. 4).

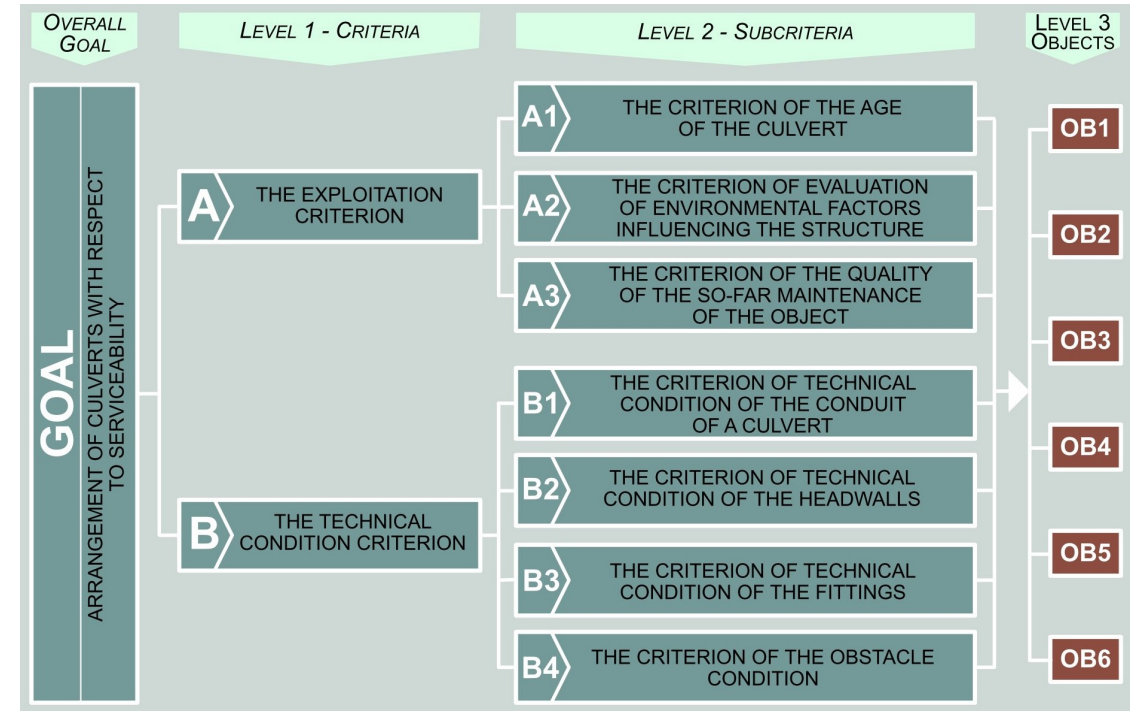

Fig. 4. Hierarchical tree with criteria classification.

It should be noted that in case of RC culverts, the following are of importance for technical condition assessment: arrangement, scope and size of the appearing cracks, as well as the depth of carbonation and other changes on the surface of concrete that can be seen with the naked eye and which indicate its gradual degradation. Regardless of the type of structure, in case one non-complaint with the biding technical standards is found, such culvert is subject to exchange for a new one.

Bearing capacity of the structure is another significant criterion which was not included in the algorithm. On the basis of the carried out calculations it was found that all analysed 
culverts met the bearing capacity condition with reference to the biding standards and criterion. Therefore, introducing this criterion would not generate any diversification of assessments and it was omitted as a result.

\subsection{The conceptual framework}

\subsubsection{The AE FAHP}

The following is the calculation sequence with the use of the modified EA FAHP method (Phase II), which leads to obtaining the weight vector of the criteria (the original notation of the AHP method was retained, the " $\sim$ symbol was used to mark the values expressed with the use of triangular fuzzy numbers) [1]:

- evaluation by performing comparison in pairs of the criteria (sub-criteria) on the same level of the hierarchical tree in the presence of a criterion form a higher level:

$$
\widetilde{A}=\left(\widetilde{a}_{i j}\right)_{n x n}=\left[\begin{array}{cccc}
\widetilde{a}_{11}=(1,1,1) & \widetilde{a}_{12} & \ldots & \widetilde{a}_{1 n} \\
\widetilde{a}_{21} & \widetilde{a}_{22}=(1,1,1) & \ldots & \widetilde{a}_{2 n} \\
\vdots & \vdots & \ddots & \vdots \\
\widetilde{a}_{n 1} & \tilde{a}_{n 2} & \ldots & \widetilde{a}_{n n}=(1,1,1)
\end{array}\right]
$$

whereas:

$$
\widetilde{a}_{i j}=\left[\widetilde{a}_{j i}\right]^{-1}=\left(l_{i j}, m_{i j}, u_{i j}\right)^{-1}=\left(\frac{1}{u_{i j}}, \frac{1}{m_{i j}}, \frac{1}{l_{i j}}\right)
$$

in which:

$l_{i j}, m_{i j}, u_{i j} \quad-$ denotes triangular fuzzy numbers.

- verification of correctness of the arrangement of assessments with the use of the CR consistency ratio obtained for the modal values of fuzzy numbers:

$$
C R=\frac{\lambda_{\max }-n}{(n-1) \cdot R I}<0,1
$$

in which:

$\lambda_{\max } \quad-\quad$ the maximum value of the eigenvector of a matrix A created from modal values of fuzzy numbers,

$n \quad-\quad$ the rank of a matrix A (the number of criteria, sub-criteria and objects being compared),

$R I \quad-\quad$ the random indicator of inconsistency in assigning assessments, dependent on the number of elements under consideration and developed with the use of statistical processing of numerous computer simulations (Table 2).

Table 2. Values of the $R I$ indicator depending on $n$ [5]

\begin{tabular}{|c|ccccccccccccccc|}
\hline$n$ & 1 & 2 & 3 & 4 & 5 & 6 & 7 & 8 & 9 & 10 & 11 & 12 & 13 & 14 & 15 \\
\hline$R I$ & 0.00 & 0.00 & 0.58 & 0.90 & 1.12 & 1.24 & 1.32 & 1.41 & 1.45 & 1.49 & 1.51 & 1.48 & 1.56 & 1.57 & 1.59 \\
\hline
\end{tabular}

- calculation of the $S_{i}$ indicator of synthetic measurement of assessments according to the corrected equation suggested by Wang and Elhag $[2,6]$ :

$$
\widetilde{S}_{i}=\frac{\tilde{R S_{i}}}{\sum_{j=1}^{n} \tilde{R} S_{j}}=\left(\frac{\sum_{j=1}^{n} l_{i j}}{\sum_{j=1}^{n} l_{i j}+\sum_{k=1, k \neq i}^{n} \sum_{j=1}^{n} u_{k j}}, \frac{\sum_{j=1}^{n} m_{i j}}{\sum_{k=1, k \neq i}^{n} \sum_{j=1}^{n} m_{k j}}, \frac{\sum_{j=1}^{n} u_{i j}}{\sum_{j=1}^{n} u_{i j}+\sum_{k=1, k \neq i}^{n} \sum_{j=1}^{n} l_{k j}}\right)
$$

in which: 
$\tilde{R S_{i}}$ - the sum of values of the $i$-th row of the matrix of partial assessments.

- components of the weight vector expressed with the use of crisp values might be obtained from the following formula:

$$
W_{i}=S_{i}\left(\widetilde{S}_{i}\right)=\frac{l_{i}+m_{i}+u_{i}}{3}
$$

finally, after standardisation:

$$
W_{i}^{\prime}=\frac{S_{i}}{\sum_{i=1}^{n} S_{i}}
$$

\subsubsection{The Fuzzy TOPSIS}

The calculation sequence with the use of the Fuzzy TOPSIS method (Phase III) is analogous to the classic TOPSIS one and the difference is that mathematical operations need to be adapted to fuzzy numbers [3]. The alternatives under consideration (the assessed objects) are compared with reference alternatives: an ideal and a negative ideal. Determining the arrangement consists in calculating the distance from reference alternatives for each alternative, as well as finding component values of the ranking vector.

- Structure of a decision matrix

in which:

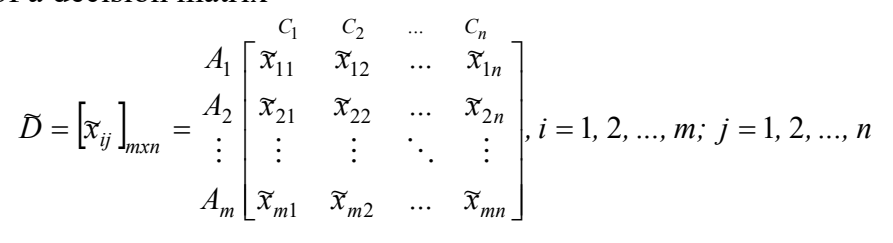

$m$ - the number of alternatives, $n-$ the number of sub-criteria.

- Standardisation of a decision matrix $\widetilde{R}=\left[\widetilde{v}_{i j}\right]_{m x n}$

for stimulants

$$
\widetilde{r}_{i j}=\left(\frac{l_{i j}}{u_{j}^{+}}, \frac{m_{i j}}{u_{j}^{+}}, \frac{u_{i j}}{u_{j}^{+}},\right), u_{j}^{+}=\max _{i} u_{i j}
$$

for destimulants

$$
\widetilde{r}_{i j}=\left(\frac{l_{j}^{-}}{u_{i j}}, \frac{l_{j}^{-}}{m_{i j}}, \frac{l_{j}^{-}}{l_{i j}},\right), l_{j}^{-}=\min _{i} l_{i j}
$$

weighted standardised decision matrix (individual matrix values are obtained by multiplying the standardised fuzzy numbers by weight factors of the criteria vector) $\widetilde{V}=\left[\widetilde{v}_{i j}\right]_{m \times n}$

$$
\widetilde{v}_{i j}=\widetilde{r}_{i j} \otimes w_{i j}
$$

- determining the coordinates of the $\tilde{A}^{+}$fuzzy positive ideal solution (FPIS) and the $\tilde{A}^{-}$ fuzzy negative ideal solution (FNIS):

$$
\begin{aligned}
& \widetilde{A}^{+}=\left(\max _{i}\left(\widetilde{v}_{i 1}\right), \max _{i}\left(\widetilde{v}_{i 2}\right), \ldots, \max _{i}\left(\widetilde{v}_{i n}\right)\right)=\left(\widetilde{v}_{1}^{+}, \widetilde{v}_{2}^{+}, \ldots, \widetilde{v}_{n}^{+}\right) \\
& \widetilde{A}^{-}=\left(\min _{i}\left(\widetilde{v}_{i 1}\right), \min _{i}\left(\widetilde{v}_{i 2}\right), \ldots, \min _{i}\left(\widetilde{v}_{i n}\right)\right)=\left(\widetilde{v}_{1}^{-}, \widetilde{v}_{2}^{-}, \ldots, \widetilde{v}_{n}^{-}\right)
\end{aligned}
$$

- calculating the distance of alternatives from model solutions that is an ideal and a negative ideal respectively: 


$$
d_{i}^{+}=\sum_{j=1}^{n} d\left(\widetilde{v}_{i j}, \widetilde{v}_{j}^{+}\right) \quad d_{i}^{-}=\sum_{j=1}^{n} d\left(\widetilde{v}_{i j}, \widetilde{v}_{j}^{-}\right)
$$

whereas the distance between two triangular fuzzy numbers $\widetilde{x}_{1}=\left(l_{1}, m_{1}, u_{1}\right)$ and $\widetilde{x}_{2}=\left(l_{2}, m_{2}, u_{2}\right)$ was defined as follows:

$$
d\left(\widetilde{x}_{1}, \widetilde{x}_{2}\right)=\sqrt{\frac{1}{3}\left[\left(l_{1}-l_{2}\right)^{2}+\left(m_{1}-m_{2}\right)^{2}+\left(u_{1}-u_{2}\right)^{2}\right]}
$$

- calculating the ranking vector of alternatives:

$$
S_{i}=\frac{d_{i}^{-}}{d_{i}^{+}+d_{i}^{-}}
$$

\section{Numerical illustration}

The numerical procedure has been developed with the use of Matlab program. Final components of the weight vector were given in Table 3. The values given in Table 3 were obtained with the use of the EA FAHP method and values of the CR consistency ratio for individual matrices were in the range from 0.000 to 0.24 . Table 4 contains modal values of initial assessments of culverts against the sub-criteria for the Fuzzy TOPSIS method. They constitute a vector of technical condition of individual components and facilitate prompt indication of crucial parameters which are most dangerous for the condition of a culvert. Components of the $\boldsymbol{S}_{\boldsymbol{i}}$ ranking vector being decisive for arranging culverts were given in Table 5. The values given in all Tables were rounded to four decimal places.

Table 3. Components of the $\mathrm{W}$ weight vector of the sub-criteria used for further calculations in the Fuzzy TOPSIS method.

\begin{tabular}{|c|c|c|c|c|c|c|c|}
\cline { 2 - 8 } \multicolumn{1}{c|}{} & $\mathrm{A} 1$ & $\mathrm{~A} 2$ & $\mathrm{~A} 3$ & $\mathrm{~B} 1$ & $\mathrm{~B} 2$ & $\mathrm{~B} 3$ & $\mathrm{~B} 4$ \\
\hline $\mathrm{W}$ & 0.0149 & 0.0528 & 0.1145 & 0.4897 & 0.1878 & 0.0898 & 0.0453 \\
\hline
\end{tabular}

Table 4. Initial assessments of objects against the sub-criteria in the form of modal values.

\begin{tabular}{|c|c|c|c|c|c|c|c|}
\hline \multirow{2}{*}{ Object } & \multicolumn{7}{|c|}{ Sub-criterion initial assessment } \\
\cline { 2 - 9 } & A1 & A2 & A3 & B1 & B2 & B3 & B4 \\
\hline OB1 & 5 & 3 & 4 & 7 & 4 & 7 & 6 \\
\hline OB2 & 7 & 3 & 8 & 9 & 7 & 5 & 6 \\
\hline OB3 & 4 & 7 & 8 & 9 & 9 & 5 & 8 \\
\hline OB4 & 4 & 4 & 4 & 4 & 6 & 4 & 7 \\
\hline OB5 & 3 & 4 & 6 & 4 & 3 & 2 & 4 \\
\hline OB6 & 3 & 8 & 5 & 4 & 3 & 4 & 8 \\
\hline
\end{tabular}

Table 5. Rank order of culverts.

\begin{tabular}{|c|c|c|c|c|c|c|}
\cline { 2 - 7 } \multicolumn{1}{c|}{} & OB3 & OB2 & OB1 & OB4 & OB6 & OB5 \\
\hline RANKING & 1 & 2 & 3 & 4 & 5 & 6 \\
\hline S & 0.793 & 0.743 & 0.616 & 0612 & 0.529 & 0.509 \\
\hline
\end{tabular}

While analysing the obtained results, it was found that the highest final assessment was given to the OB3 and OB2 culverts, 0.793 and 0.743 respectively, and their technical condition was qualified as insufficient. What was of utmost importance as far as the poor result was the low quality of the so-far maintenance, as well as poor technical condition of the pipe (OB2) or frame (OB3) and headwalls (Table 5). 


\section{Conclusions and future research directions}

An innovative integrated calculation algorithm which makes use of the modified EA FAHP and the Fuzzy TOPSIS methods has been applied in the presented model, which allows to reflect the actual assessment processes, for example, of the technical condition of culverts. It facilitates creation of a dynamic model to classify culverts at the determined time intervals with the possibility to enter an adjustment in case random events occur. Application of the EA FAHP method in the phase of criteria evaluation arouse from the possibility to verify the correctness of the assessments. Unfortunately, the method does not make it possible to analyse any number of objects and therefore the Fuzzy TOPSIS algorithm was applied in the phase of culvert evaluation. The aggregated calculation algorithm is characterised by a fairly clear computational procedure that can be easily entered in the Matlab or Excel programs. What proved extremely helpful was the application of assessments in the form of linguistic variables, which facilitate quality description used most frequently in descriptions of technical condition, as well as representing the information obtained with the use of various methods and diagnostic techniques. The possibility to take into consideration the questionable character of assessments, incomplete data and group evaluation made by teams of experts, which are particularly significant in case of breakdowns, is yet another advantage of this method.

The proposed model is suitable for the following applications:

- monitoring and diagnostics - providing the possibility to evaluate technical condition of a given culvert on a daily basis, as well as plan current maintenance works,

- forecasting - this is facilitated by current archiving of data concerning a given culvert and evaluating the impact of the undertaken repair works on its use as a result.

The fact that it is possible to analyse only culverts with the same number of components (belonging to a homogeneous set as expressed in mathematics), but ones in which any materials have been used, is a restriction to the use of the algorithm.

The computational model was verified on a group of six randomly selected railway culverts and the obtained results confirm its correctness as well as a high application potential. The possibility to manage an unlimited set of culverts is a practical aspect of the proposed model.

\section{References}

1. D.-Y. Chang, Application of the extent analysis method on fuzzy AHP, European Journal of Operational Research, 95 (1996)

2. Y-M. Wang, T. M. S. Elhag, On the normalization of interval and fuzzy weights, Fuzzy Sets and Systems, 157 (2006)

3. T. Yang, C.C. Hung, Multiple-attribute decision making methods for plant layout design problem, Robotics and Computer-Integrated Manufacturing, 23(1) (2007)

4. P. Jakiel, D. Fabianowski, FAHP model used for assessment of highway RC bridge structural and technological arrangements, Expert Systems with Applications 42 (2015)

5. T. L. Saaty, Fundamentals of decision making and priority theory with the analytic hierarchy process, RWS Publications (Pitsburgh, 1994)

6. Y-M. Wang, T. M. S. Elhag, $A$ Fuzzy Group Decision Making approach for bridge risk assessment, Computers \&Industrial Engineering, 53 (2007) 